\title{
Biflavonoids inhibit the production of aflatoxin by Aspergillus flavus
}

E. Gonçalez, J.D. Felicio and M.M. Pinto
Laboratório de Produtos Naturais, Centro de Sanidade Animal, Instituto Biológico, São Paulo, SP, Brasil

\section{Correspondence}

E. Gonçalez

Laboratório de Produtos Naturais

Centro de Sanidade Animal

Instituto Biológico

Av. Cons. Rodrigues Alves, 1252

04014-002 São Paulo, SP

Brasil

Fax: + 55-11-5087-1754

E-mail: goncalez@biologico.br

Publication supported by FAPESP

Received May 7, 2001

Accepted August 27, 2001

\section{Abstract}

The biflavonoids 6,6"-bigenkwanin, amenthoflavone, 7,7"-dimethoxyagastisflavone and tetradimethoxybigenkwanin isolated from Ouratea species were tested for inhibitory activity on Aspergillus flavus cultures. Suspensions of Aspergillus flavus spores were inoculated into $50 \mathrm{ml}$ of YES medium at different biflavonoid concentrations: 5 and $10 \mu \mathrm{g} / \mathrm{ml}$ for 6,6"-bigenkwanin, amenthoflavone and 7,7"-dimethoxyagastisflavone, and 5, 10, 15 and $20 \mu \mathrm{g} / \mathrm{ml}$ for tetradimethoxybigenkwanin. The four biflavonoids showed inhibitory activity on aflatoxin $\mathrm{B} 1$ and $\mathrm{B} 2$ production $(\mathrm{P}<0.001)$, but did not inhibit fungal growth at the concentration tested $(\mathrm{P}>0.05)$. These results show that biflavonoids can be used for the development of agents to control aflatoxin production.

Aflatoxins are secondary metabolites of Aspergillus flavus and A. parasiticus which have been shown to be toxigenic, carcinogenic, mutagenic, and teratogenic to different animal species (1). Evidence indicates that these toxins may also be involved in the etiology of human liver cancer in certain parts of the world (2).

Extracts of some plants are toxic to fungi and may be useful for controlling fungal growth and mycotoxin production (3). Substances isolated from plants such as flavonoids, isoflavonoids and biflavonoids, besides other activities, have shown activity against some aspects of fungal metabolism (4-7).

The utilization of these natural compounds as substitutes for conventional fungicides in order to prevent contamination by aflatoxins has been considered because some flavonoids are biologically active against $A$. flavus and A. parasiticus $(6,7)$.

The present study investigated the effect of the biflavonoids 6,6"-bigenkwanin (I); tetradimethoxybigenkwanin (II); amenthoflavone (III), and 7,7"-dimethoxyagastisflavone (IV) (Figure 1) isolated from Ouratea sp on A. flavus growth and aflatoxin B1 (AFB1) and B2 (AFB2) production. Information about structure/activity relationships is also reported.

6,6"-Bigenkwanin (I) was obtained from Ouratea spectabilis and 6,6"-tetradimethoxybigenkwanin (II) was obtained by methylation of compound I as described by Felicio et al. (8). Amenthoflavone (III) was obtained from $O$. multiflora as previously described by Felicio et al. (9). The biflavone 7,7"dimethoxyagastisflavone (IV) was isolated from $O$. parviflora leaves by the method of 
Park et al. (10).

A. flavus was used to evaluate fungal growth and AFB1 and AFB2 inhibition. The semisynthetic YES culture medium was used for aflatoxin production (11). The method used here was previously described by Mallozzi et al. (6). Briefly, A. flavus IMI 190 (International Mycology Institute, London, UK) was grown on potato dextrose agar (Difco Laboratories, Detroit, MI, USA) plates for 10 days at $25^{\circ} \mathrm{C}$ until well sporulated. Suspensions of $A$. flavus spores were inoculated into $50 \mathrm{ml}$ of YES medium containing different biflavonoid concentrations, i.e., 0 (control), 5 and $10 \mu \mathrm{g} / \mathrm{ml}$ for 6,6 "-bigenkwanin, amenthoflavone and 7,7"-dimethoxyagastisflavone, and 0 (control), 5, 10, 15 and $20 \mu \mathrm{g} / \mathrm{ml}$ for tetradimethoxybigenkwanin. Three replicates were performed for each dilution of the biflavonoids tested. Aflatoxins were extracted by adding chloroform to the culture medium, shaking and separating the chloroform phase. Extracts were analyzed by thin layer chromatography against an AFB1 and AFB2 standard. Aflatoxins were quantified by photodensitometry (Shimadzu, CS9000) of the spots.

Statistical analysis was performed using one-way analysis of variance (ANOVA) and the Tukey-Kramer multiple comparisons test with the level of significance set at $\mathrm{P}<0.05$ and $\mathrm{q}>4.457$.

The different concentrations of the biflavonoids (I-IV) (Figure 1) tested showed inhibitory activity on AFB1 and AFB2 production by $A$. flavus. The $A$. flavus used with control produced $188.6 \mu \mathrm{g} / \mathrm{ml}$ of AFB1 and $12.58 \mu \mathrm{g} / \mathrm{ml}$ of AFB2 while the fungus treated with biflavonoids I, II, III and IV at $5 \mu \mathrm{g} / \mathrm{ml}$ concentration produced 56.58, 42.65, 37.42 and $45.19 \mu \mathrm{g} / \mathrm{ml}$ of AFB1, respectively, and $2.38,2.87,1.88$ and $3.17 \mu \mathrm{g} / \mathrm{ml}$ of AFB2, respectively. At $10 \mu \mathrm{g} / \mathrm{ml}$ concentration the results obtained were $22.58,22.29,18.41$ and $27.56 \mu \mathrm{g} / \mathrm{ml}$ of AFB1 and 2.34, 0.75, 1.11 and $1.55 \mu \mathrm{g} / \mathrm{ml}$ of AFB2 for compounds I, II, III and IV, respectively. The inhibition was considered extremely significant $(\mathrm{P}<0.001)$. The effects of biflavonoids on AFB1 and AFB2 are shown in Figure 2. Tetradimethoxybigenkwanin concentrations above $10 \mu \mathrm{g} / \mathrm{ml}$ did not show a significantly different inhibitory activity when compared with concentrations below $10 \mu \mathrm{g} / \mathrm{ml}$.

In order to investigate the magnitude of the fungal response, the inhibitory activities of the different biflavonoids were compared, indicating that there were no statistically significant differences $(\mathrm{P}>0.05)$ probably due to the structural similarity of the four
Figure 1. Chemical structure of four biflavonoids: 6,6"-bigenkwanin (I), tetradimethoxybigenkwanin (II), amenthoflavone (III) and 7,7"-dimethoxyagastisflavone (IV) isolated from Ouratea species, and tested here in cultures of Aspergillus flavus.

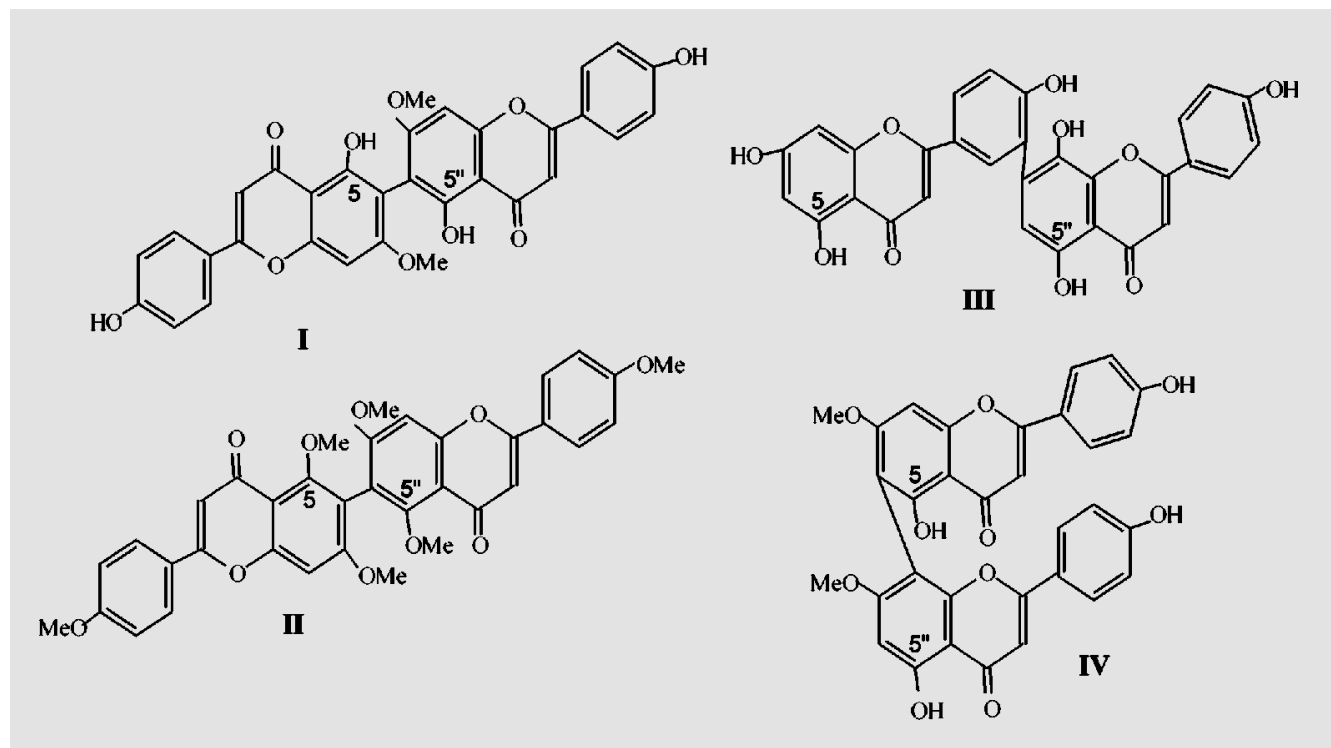


biflavonoids. Furthermore, there were no variations in the substitution patterns for the compounds, with the four biflavonoids showing the same oxidation patterns. Ring A of compounds I, III and IV has hydroxyl groups at the 5 and 5 " positions but compound II has a methoxyl group at the same positions. On the other hand, Weidenborner et al. (4) detected a high antifungal activity of the flavonoids, guaranteed by at least two methoxyl groups in the A ring, one at each of the 5 position.

However, compound III showed the highest inhibitory action (90.2\%) on AFB1 production compared to the other biflavonoids at $10 \mu \mathrm{g} / \mathrm{ml}$ concentration. On the other hand, compound II showed the highest inhibitory activity on AFB2 production (94.0\%) at 10 $\mu \mathrm{g} / \mathrm{ml}$ concentration. The methylation of compound I did not result in a change in activity in AFB 1 production ( 88.0 and $88.2 \%$ for the non-methylated and methylated compound, respectively), but AFB2 production was changed to 81.39 and $94.03 \%$, respectively.

However, activity may be not related to the interflavonoid linkage because compounds I, III and IV showed similar inhibitory activity. The linkage between the two flavone units differs between compounds, occurring in the 6 and 6 " carbons in compounds I and II, in the 3 ' and 7" carbons in compound III and in the 6 and 8 " carbons in compound IV.

Mycelial dry weight was used to evaluate fungal growth. The tested biflavonoids did not inhibit $A$. flavus growth at the concentrations tested. Previous studies with biflavonoids have demonstrated a strong antifungical action by amenthoflavone (12), which was not observed in the present study, in which no inhibition of A. flavus growth occurred.

The results obtained here show that bifla-

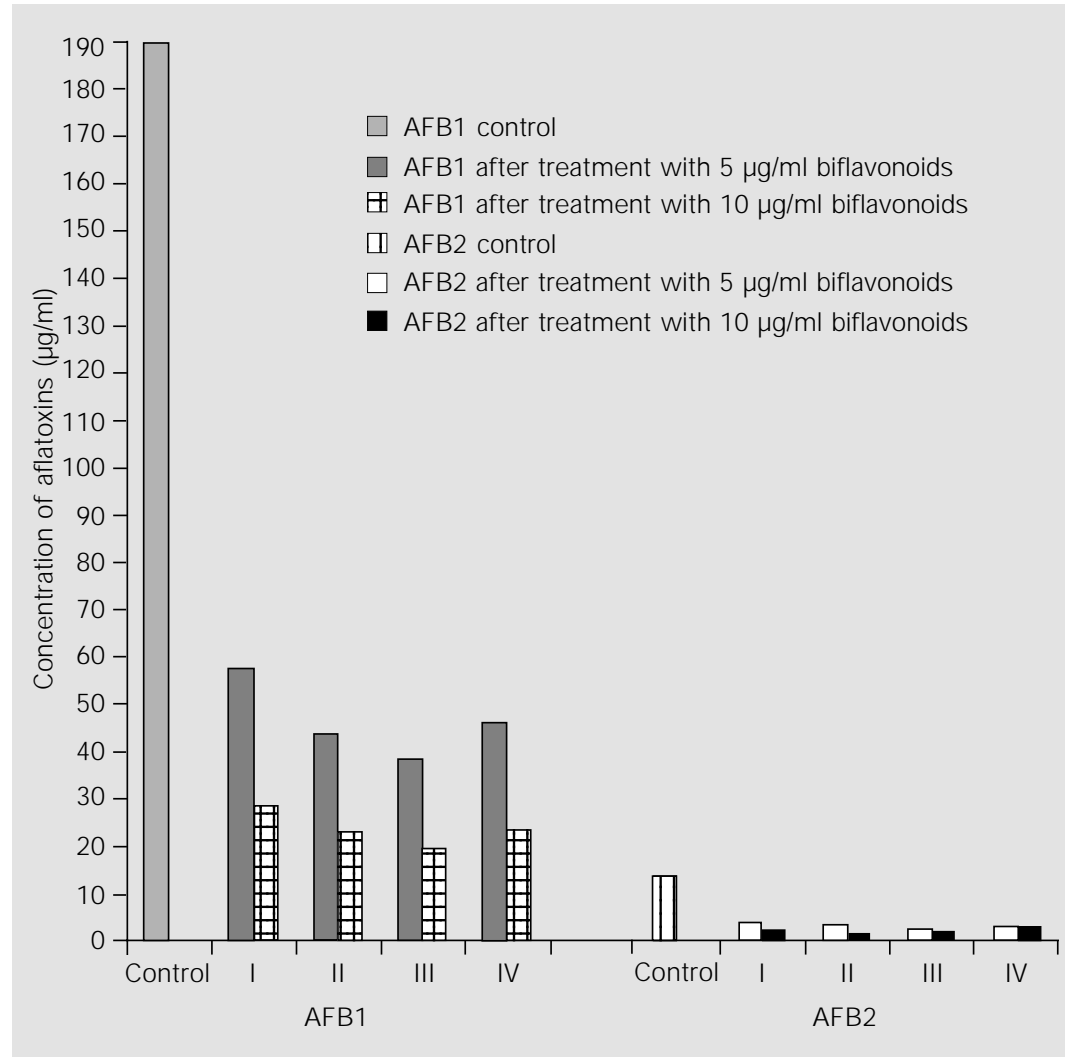

Figure 2. Production of aflatoxin B1 and B2 (AFB1 and AFB2, respectively) by Aspergillus flavus (IMI 190) cultures after treatment with different concentrations $(5,10 \mu \mathrm{g} / \mathrm{ml}$ and control) of the biflavonoids 6,6"-bigenkwanin (I), tetradimethoxybigenkwanin (II), amenthoflavone (III), and 7,7"-dimethoxyagastisflavone (IV). Three replicates were performed for each dilution. The four biflavonoids showed inhibitory activity on AFB1 and AFB2 production $(\mathrm{P}<0.001)$. The A. flavus used with control produced $188.6 \mu \mathrm{g} / \mathrm{ml}$ of AFB1 and $12.58 \mu \mathrm{g} /$ $\mathrm{ml}$ of AFB2 while the fungus treated with biflavonoids I, II, III and IV at $5 \mu \mathrm{g} / \mathrm{ml}$ concentration produced $56.58,42.65,37.42$ and $45.19 \mu \mathrm{g} / \mathrm{ml}$ of AFB1, respectively, and 2.38, 2.87, 1.88 and $3.17 \mu \mathrm{g} / \mathrm{ml}$ of AFB2, respectively. At $10 \mu \mathrm{g} / \mathrm{ml}$ concentration, the results obtained were 22.58, 22.29, 18.41 and $27.56 \mu \mathrm{g} / \mathrm{ml}$ of AFB1 and 2.34, 0.75, 1.11 and $1.55 \mu \mathrm{g} / \mathrm{ml}$ of AFB2 for compounds I, II, III and IV, respectively.

vonoids were more active in aflatoxin production at lower concentrations than the flavonoids and anthocyanidins studied by Mallozzi et al. (6) and Norton (7), which may indicate that substances of dimeric shape would cause stronger activity. It is clear that these substances are important for the development of agents to control AFB1 and AFB2 production. 


\section{References}

1. Fan JJ \& Chen JH (1999). Inhibition of aflatoxin-producing fungi by Welsh onion extracts. J ournal of Food Protection, 62: 414-417.

2. Bullerman LB (1974). Inhibition of aflatoxin production by cinnamon. J ournal of Food Science, 39: 1163-1165.

3. Steinhart CE, Doyle ME \& Cochrane BA (1996). Food Safety 1996. Marcel Dekker, Inc., New York, NY, USA, 376-394.

4. Weidenbomer $\mathrm{M}$, Hindorf $\mathrm{H}$, J ha $\mathrm{CH} \&$ Tsotsonos P (1990). Antifungical activity of flavonoids against storage fungi of the genus Aspergillus. Phytochemistry, 29: 1103-1105.

5. Weidenborner $\mathrm{M}$, Hindorf $\mathrm{H}$, J ha $\mathrm{CH}$, Tsotsonos P \& Egge H (1989). Antifungical activity of isoflavonoids against storage fungi of the genus Aspergillus. Phy- tochemistry, 28: 3317-3319.

6. Mallozzi MAB, Corrêa $B$, Haraguchi $M \&$ Brignani FN (1996). Effect of flavonoids on Aspergillus flavus growth and aflatoxin production. Revista de Microbiologia, 27: 161-167.

7. Norton RA (1999). Inhibition of aflatoxin B1 biosynthesis in Aspergillus flavus by anthocyanidins and related flavonoids. J ournal of Agricultural and Food Chemistry, 47: 1230-1235.

8. Felicio JD, Gonçalez E, Braggio MM, Constantino L, Albasini A \& Lins AP (1995). Inhibition of lens aldose reductase by biflavones from Ouratea spectabilis. Planta Medica, 61: 217-220.

9. Felicio JD, Rossi MH, Park HR, Gonçalez E, Braggio MM, David J M \& Cordeiro I (2001). Bioflavonoids from Ouratea multi- flora. Fitoterapia, 72: 443-455.

10. Park HR, Felicio JD, Rossi MH, Pak A, Gonçalez E \& Braggio MM (2000). Chemical constituents of Ouratea parviflora and Ouratea multiflora (Ochnaceae). 22nd IUPAC International Symposium on the Chemistry of Natural Products, São Carlos, SP, Brazil, September 3-8, 2000, PPA 017.

11. Davis ND, Diener UL \& Eldridge DW (1966). Production of aflatoxins B1 and G1 by Aspergillus flavus in semisynthetic medium. Applied Microbiology, 14: 378380.

12. Królicki LZ (1984). Investigation of antifungal effect of flavonoids. Hebapolonica, 130: 55-57. 